\title{
TURISMO CHINO EMISOR: ESTADO DE LA CUESTIÓN Y AGENDA
}

\author{
Aureli Lojo* \\ Departamento de Geografía. \\ Universidad Autónoma de Barcelona \\ Aureli.lojo@uab.cat
}

\section{RESUMEN}

Este artículo presenta un estado de la cuestión de la investigación acerca del turismo chino emisor y tiene como objetivos conocer qué áreas temáticas conforman la investigación sobre este fenómeno y qué lagunas de conocimiento se pueden encontrar desde una perspectiva geográfica. El texto desarrolla una revisión sistemática de 124 artículos publicados en los últimos 10 años procedentes de 16 revistas académicas. Los resultados identifican las líneas de investigación existentes, destacan que la perspectiva geografía apenas ha sido desarrollada y sugieren posibles áreas de futura investigación.

Palabras clave: Turismo chino, Estado de la cuestión, revisión sistemática de la bibliografía, revistas académicas, Geografía del turismo.

\section{ABSTRACT}

This paper main contribution is the offering of a systematic review of the existing literature on Chinese outbound tourism, aimed at assessing the nature and streams of research into this phenomenon and finding gaps in knowledge from the geographical perspective. 124 articles published during the last 10 years from 16 academic journals were included

Fecha de recepción: enero 2015.

Fecha de aceptación: julio 2016.

* Aureli Lojo es investigador del Departamento de Geografía de la Universidad Autónoma de Barcelona y doctorando del Programa de Geografía de la misma universidad. Este estudio está apoyado por el Ministerio de Educación, Cultura y Deporte del Gobierno de España (FPU014/034369) y por el Ministerio de Economía y Competitividad del Gobierno de España (CSO2013-41374-R). 
for review. The paper identifies and structures the main research streams, indicates that the geographical perspective is mostly absent and suggest main paths for further research on the Chinese outbound tourism area.

Keywords: Chinese outbound tourism, State-of-the-art, systematic literature review, academic journals, Geography of tourism.

\section{INTRODUCCIÓN Y OBJETIVOS}

En los últimos años el patrón histórico de flujos turísticos internacionales ha experimentado un importante cambio debido a la irrupción del turismo chino y desde 2013 China es el primer país emisor de turistas a nivel mundial. Además, también es la primera potencia mundial en gasto turístico en el extranjero. Esta influencia es notable en los destinos turísticos de Asia y Oceanía: China es el primer mercado emisor para Corea del Sur y Japón y el segundo mercado emisor en Australia y Nueva Zelanda. En Europa, Francia recibió cerca de 2 millones de turistas chinos en 2015 (ChinaDaily, 2015) y en Francia este mercado supone el segundo número más elevado de visitantes después de los estadounidenses, en caso de no tener en cuenta a los viajeros europeos. España en el mismo año recibió 400.000 turistas chinos: con un aumento del $35,7 \%$ respecto al año anterior es el mercado emisor con mayor crecimiento después del surcoreano (INE, 2016). En la actualidad muchos países tratan de rediseñar sus servicios y atractivos turísticos para adaptarse a estos nuevos visitantes, cuyo número se ha multiplicado por cinco desde inicios del siglo XXI (Urry y Larsen, 2011).

El turismo chino ha recibido creciente atención por parte de los académicos y recientemente se han publicado cinco revisiones de la literatura acerca de la investigación del turismo chino emisor. El turismo emisor es aquel que abarca las actividades realizadas por un turista fuera de su país de residencia. En cuanto al turismo chino, Keating y Kriz (2008) se centraron únicamente en revisar los estudios sobre la imagen turística y la elección del destino, creando un modelo que integra ambas dimensiones. Cai et al. (2008) revisaron 30 artículos y mediante un meta-análisis identificaron la existencia de tres áreas principales: la investigación general sobre el mercado turístico; la investigación sobre un destino concreto a partir de datos secundarios; y la investigación sobre un destino concreto a partir de datos primarios. El trabajo de Tse (2015) utiliza una aproximación ontológica y clasifica 80 artículos en tres áreas: investigación relacionada con los destinos, con el turista y con el mercado emisor. Keating et al. (2015) han analizado las publicaciones en únicamente tres revistas académicas y han detectado tres etapas en la investigación de este tema: antes de 1992, entre 1993 y 2002, y de 2003 a 2012. Por último, Jin y Wang (2016), a partir de 161 artículos han presentado un análisis bibliométrico y también han segmentado las aportaciones en diferentes áreas del conocimiento: psicología, marketing, gestión de empresas, economía, historia, sociología y ciencias políticas.

Los artículos dedicados al turismo chino internacional conforman un rico y variado campo de conocimiento. Para facilitar futuras investigaciones es necesario sintetizar las tendencias actuales y emergentes, conocer las diferentes temáticas de estudio y comprender el pensamiento actual en este campo. A este fin, la presente investigación trata de contribuir a 
la literatura académica sobre turismo mediante una revisión de los artículos actuales publicados sobre turismo chino emisor, prestando especial atención a la perspectiva geográfica para ofrecer un estado de la cuestión e indagar en futuras áreas de investigación. Las preguntas de trabajo son las siguientes: ¿cuáles son las líneas y temáticas que se han estudiado respecto al turismo chino internacional? Desde la perspectiva geográfica, ¿cuáles son las principales lagunas de investigación que pueden ser abordadas en el futuro?

\section{MÉTODOLOGÍA}

\section{II.1. Revisión sistemática de la literatura}

Las revisiones de literatura suponen contribuciones académicas importantes porque reconocen sinergias en las publicaciones existentes e identifican lagunas de conocimiento, lo que permite la toma de decisiones basadas en evidencias (Callahan, 2014; Farinós, 2008; López-Guzmán et al., 2013). Un estado de la cuestión bien realizado identifica las cuestiones actuales, ofrece nuevas perspectivas y señala áreas para futura investigación (Booth et al., 2012). Si además se realiza de forma sistemática, la revisión de la literatura debe formularse de manera transparente y explicando en detalle cómo se ha realizado: exponiendo las bases de datos utilizadas, indicando los términos de búsqueda, los motivos argumentados en la toma de decisiones y el método de análisis (Saunders et al., 2012). Garza-Reyes (2015) divide las fases de la revisión de la literatura en función de los objetivos y los diferentes métodos en: (1) la formulación de la pregunta de investigación, (2) la localización, selección y evaluación inicial de la literatura relevante, (3) la síntesis y análisis de los artículos y (4) la comunicación de los resultados. En el presente estudio, la formulación de la pregunta de investigación se ha señalado en la introducción. A continuación se explican las decisiones y métodos propios de la segunda y tercera fases.

\section{II.2. Localización y selección de los estudios}

Las fuentes de datos utilizados han sido revistas académicas sobre turismo y únicamente se han considerado artículos de investigación. Se han examinado cuatro rankings de revistas sobre turismo: el Social Science Citation Index y los ranking de Hall (2011), McKercher et al. (2006), Ryan (2005) y Pechlaner et al. (2004). Siguiendo el modelo de Jin y Wang (2016), las revistas elegidas debían figurar en tres de los cuatro rankings, con lo que quince revistas han sido seleccionadas: Tourism Management, Annals of Tourism Research, Journal of Travel Research, International Journal of Hospitality Management, Journal of Hospitality and Tourism Research, International Journal of Contemporary Hospitality Management, Journal of Travel and Tourism Marketing, Cornell Hospitality Quarterly, Tourism Economics, Asia-Pacific Journal of Tourism Research, Journal of Hospitality Marketing and Management, International Journal of Tourism Research, Current Issues in Tourism, Tourism Analysis y Journal of Sustainable Tourism. Además, se ha añadido la revista Journal of China Tourism Research, debido a que es la única revista cuyo principal foco de atención es el turismo chino y en la que se han publicado numerosos artículos sobre el turismo chino emisor. 
Un estado de la cuestión utiliza las aportaciones más actuales para definir la situación reciente de la investigación sobre un tema determinado. Por este motivo, se han elegido los artículos producidos en los últimos 10 años, desde enero de 2006 hasta mayo de 2016. Se han incluido también los artículos publicados como avances online que se encuentran disponibles en las fuentes de datos. En cuanto a las bases de datos, la búsqueda se ha realizado directamente en las páginas web de cada una de las revistas, utilizando cadenas de búsqueda específicas. El turismo chino emisor es un fenómeno complejo que se estudia de forma interdisciplinar, por lo que es adecuado utilizar un acercamiento C-I-M-O (Context, Intervention, Mechanism, Outcomes) (Briner y Denyer, 2012). Este marco de trabajo se ha elegido para considerar las preguntas de investigación y las cadenas de búsqueda utilizadas: «China outbound», «China international», «China overseas», «Chinese outbound», «Chinese international» $\mathrm{y}$ «Chinese overseas». Se ha omitido el término «turismo» porque las búsquedas se realizaban en revistas especializadas de turismo. Así, 135 documentos respondían a los criterios de búsqueda y han sido recogidos.

Posteriormente, se ha establecido un criterio de inclusión y exclusión en función de una primera revisión del contenido de los artículos (Briner y Denyer, 2012). El criterio de exclusión se ha formulado a partir de las preguntas de investigación del presente estudio y se han descartado los artículos que únicamente estudian la demanda econométrica o que no tratan el tema del turismo chino emisor, entendiendo turismo chino emisor como el turismo procedente de la China Continental hacia otros destinos. Es decir, estudios sobre turismo emitido únicamente desde Hong Kong, Macao o Taiwán han sido omitidos. Esta elección se debe a que la agencia nacional china de turismo, la China National Tourism Administration, considera los viajes desde la China continental a las Regiones Administrativas Especiales de Hong Kong o Macao como un viaje exterior (Jin y Wang, 2016) y hay diferencias notables entre el comportamiento de los turistas procedentes de estas distintas regiones (Kim et al., 2015). Los estudios sobre previsiones de demanda siguiendo modelos econométricos también han sido excluidos ya que aportan poco al conocimiento del turismo chino como fenómeno social. Por último, se han descartado los artículos que estaban enfocados al análisis del turismo chino doméstico. Tras establecer esta primera revisión aplicando los mencionados criterios, un total de 124 artículos se han seleccionado para la siguiente fase de análisis.

\section{II.3. Análisis y síntesis}

El objetivo del análisis es examinar los estudios de forma individual y explorar como se relacionan entre sí, mientras que la síntesis es el proceso de crear un nuevo conocimiento fruto de la comprensión de la totalidad de los artículos (Denyer y Tranfield, 2009). Es habitual que el proceso comience mediante la extracción de datos de los estudios individuales para elaborar un análisis descriptivo de la muestra (indicando autores clave, evolución temporal de las publicaciones o universidades en las que se concentra la investigación sobre el tema tratado) (Briner y Denyer, 2012). La síntesis se puede realizar de forma cuantitativa, cualitativa o integrada, en función de la naturaleza de la literatura considerada. Debido al interés por tratar el turismo como un fenómeno social, a la naturaleza interdisciplinaria de la contribuciones y a la existencia de estudios cuantitativos y cualitativos en los 124 artículos considerados, se ha elegido la síntesis temática (Garza-Reyes, 2015) para construir los resultados de la revisión sistemática de la literatura realizada. 
El análisis de contenidos cualitativo se ha utilizado como técnica de investigación a partir de una categorización inicial de los resultados. Leiper (1979) considera que la actividad turística está conformada por tres elementos clave: los turistas, las regiones geográficas (inicial, de tránsito y final) y la industria turística. Según este marco, estudiar el turismo chino significa entender al turista (consumidor), los contextos (de emisión y recepción de turismo) y la industria que articula la actividad. Estos tres conceptos forman el esqueleto de la categorización preliminar de nuestro estudio. Además, se ha seleccionado el esquema conceptual temático de Pearce (2005) para determinar cinco áreas de estudio de comportamiento del turista: (1) los roles sociales, las características demográficas y las segmentaciones; (2) las motivaciones y la elección de destino; (3) imágenes y expectativas sobre un destino; (4) la experiencia en el lugar; (5) los impactos, satisfacciones y resultados de la actividad turística. Esta categorización inicial ha permitido la primera codificación individual de los 124 artículos (figura 1).

Figura 1

CLASIFICACIÓN TEMÁTICA PRELIMINAR DE LOS ARTÍCULOS

\begin{tabular}{|c|c|}
\hline CONTEXTO & Roles sociales y segmentos \\
\hline TURISTA & Imágenes servicios y expectativas de los destinos \\
\hline INDUSTRIA & $\begin{array}{l}\text { Experiencia en el lugar } \\
\text { Impactos y resultados }\end{array}$ \\
\hline
\end{tabular}

Fuente: elaboración propia.

El proceso de categorización y codificación se ha desarrollado con la comparación y contraste de los artículos sintetizados y han emergido nuevas categorías y subcategorías temáticas. Los resultados del análisis y síntesis de la literatura seleccionada se presentan en el siguiente apartado. En primer lugar se señala el análisis descriptivo de la muestra; y en segundo lugar se indican los resultados de la síntesis.

\section{RESULTADOS (1): ANÁLISIS DESCRIPTIVO Y CLASIFICACIÓN TEMÁTICA}

\section{III.1. Análisis descriptivo de la muestra}

La mayoría de los 124 artículos recogidos están centrados en el estudio del comportamiento del turista y su relación con los destinos turísticos. Este ámbito forma el segundo grupo de artículos, tal y como está presente en la figura 2. Un menor número de artículos estudian el contexto político y socioeconómico chino en que se desarrolla la actividad turística (grupo 1) y otro grupo de artículos exploran aspectos clave de la industria turística relacionada con el mercado emisor chino.

La figura 3 indica que el número de artículos ha seguido una dinámica creciente en los últimos diez años. Estos resultados sugieren que nos encontramos ante un área de estudio 
Figura 2

CLASIFICACIÓN TEMÁTICA PRELIMINAR

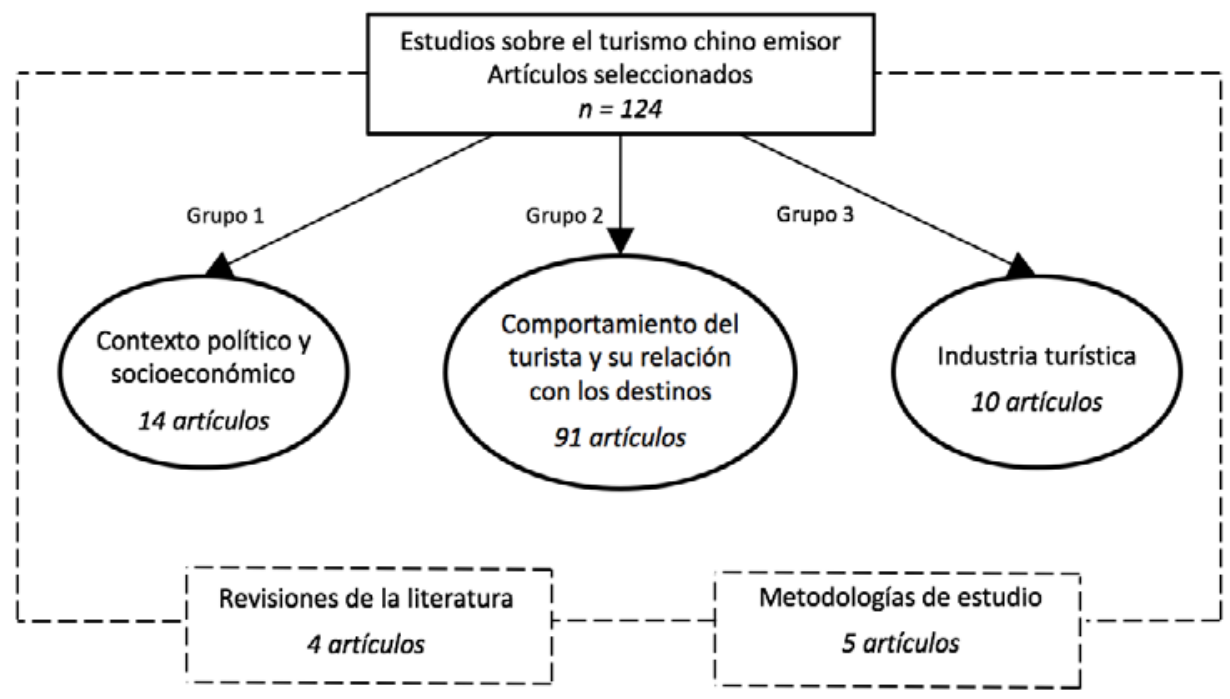

Fuente: elaboración propia.

Figura 3

AÑOS Y REVISTAS DE PUBLICACIÓN DE LOS ARTÍCULOS



Nota: El número de artículos publicados en el año 2016 es una estimación resultado de multiplicar por dos los artículos publicados en la primera mitad del año.

Fuente: elaboración propia. 
nueva y un campo emergente de investigación. En cuanto a las revistas que han publicado estos artículos, más del $50 \%$ de los artículos analizados provienen de tres publicaciones: Journal of China Tourism Research, Journal of Travel and Tourism Marketing y Asia-Pacific Journal of Tourism Research. El número más alto de artículos encontrados en estas revistas es acorde con el foco de atención de dos de las revistas, pues la primera se dedica especialmente a la investigación sobre turismo chino y la tercera, al área de Asia y el Pacífico.

En la tabla 1 podemos ver las instituciones a las que pertenecen los investigadores que han publicado sobre este tema. El 20\% de las autorías están relacionadas con The Hong Kong Polytechnic University, con 66 autores que pertenecen a esta universidad del total de 322 autores presentes en los 124 artículos. En segundo lugar encontramos la Griffith University de Australia con el $7 \%$ de las publicaciones. Estos resultados muestran la importancia del fenómeno del turismo chino emisor en la zona de Asia oriental y Oceanía, aunque también ha despertado el interés de investigadores estadounidenses.

Tabla 1

INSTITUCIONES A LAS QUE PERTENECEN LOS AUTORES DE LOS ARTÍCULOS

\begin{tabular}{lrr}
\hline Principales 10 instituciones & $\begin{array}{r}\text { Número de } \\
\text { autores (n= 322) }\end{array}$ & (Porcentaje) \\
\hline The Hong Kong Polytechnic University (Hong Kong) & 66 & 20,5 \\
Griffith University (Australia) & 23 & 7,1 \\
Zhejiang University (China) & 12 & 3,7 \\
Purdue University (Estados Unidos de América) & 10 & 3,1 \\
The University of Queensland (Australia) & 10 & 3,1 \\
The University of Waikato Management School (Nueva Zelanda) & 10 & 3,1 \\
University of South Carolina (Estados Unidos de América) & 10 & 3,1 \\
Institute for Tourism Studies (Macao) & 9 & 2,8 \\
James Cook University (Australia) & 7 & 2,2 \\
Sun Yat-sen University (China) & 7 & 2,2 \\
\hline
\end{tabular}

Nota: El número total de autores es 322 debido a que se han incluido todos los autores firmantes en los 124 artículos seleccionados. Únicamente se indican las principales 10 instituciones, aunque hay un total de 110 instituciones involucradas.

Fuente: elaboración propia.

Los estudios sobre el turismo chino emisor se pueden dividir entre aquellos que investigan el fenómeno mediante estudios de caso hacia determinados destinos (66.9\% de los artículos) y aquellos que tratan el tema sin vincularlo a ningún destino concreto $(33,1 \%)$. La tabla 2 muestra los destinos en los que se ha estudiado el turismo chino. El mayor número de artículos presente en la tabla pertenece a los que estudian el fenómeno independientemente de los destinos a los que se dirigen los turistas. 41 artículos (un 33,1\%) entran en esta categoría. En segundo lugar, un $27 \%$ de los estudios se centran en la región de Asia y un 19\% en Oceanía. En menor medida se encuentran estudios sobre EEUU y Europa. Por último, también se han producido 7 estudios 
en los que se ha comparado diferentes destinos. En cuanto a los países (o Regiones Administrativas Especiales) estudiados, sobresale Australia, seguida de Macao, EEUU, Hong Kong y Taiwán. Varios autores indican que Europa es un destino emergente para los turistas chinos (Zhu et al., 2015; Prayag et al., 2015a) y que la comprensión del turismo chino en diferentes destinos deberían estudiarse en investigaciones diferentes para comprender la singularidad de los destinos (Jin y Wang, 2016). En Europa existe la tendencia de tratar el continente de forma homogénea: de los 9 artículos vinculados a esta región, únicamente 4 tratan países de forma individual. Los países que han sido estudiados son el Reino Unido, Grecia, Alemania e Italia. Los resultados sugieren que un mayor número de estudios se podrían desarrollar sobre las áreas menos estudiadas y que son destinos importantes a nivel mundial, como Francia y España que son el primer y el tercer país en volumen de turistas en el ranking mundial.

Tabla 2

DESTINOS SOBRE LOS QUE SE ESTUDIA EL TURISMO CHINO

\begin{tabular}{|c|c|c|c|c|c|}
\hline Destino & $\begin{array}{r}\mathrm{N}^{0} \text { de } \\
\text { artículos } \\
(\mathrm{n}=124)\end{array}$ & Porcentaje & Países & $\begin{array}{r}N^{0} \text { de artículos } \\
(n=124)\end{array}$ & Porcentaje \\
\hline No específico & 41 & 33 & No específico & 41 & 33 \\
\hline Asia & 34 & 27 & Australia & 19 & 15 \\
\hline Oceanía & 23 & 19 & Macao & 9 & 7 \\
\hline América & 10 & 8 & $\begin{array}{l}\text { Estados Unidos de } \\
\text { América }\end{array}$ & 9 & 7 \\
\hline Europa & 9 & 7 & Hong Kong & 8 & 7 \\
\hline Múltiples países & 7 & 6 & Taiwán & 8 & 7 \\
\hline
\end{tabular}

Nota: En la tabla de la derecha únicamente se indican los cinco destinos con mayor número de estudios de casos. Fuente: elaboración propia.

\section{III.2. Mapa conceptual sobre el turismo chino emisor}

Dentro de los estudios dedicados al contexto político y social en el que se desarrolla el turismo (grupo 1), los investigadores han prestado atención a los determinantes políticos y socioeconómicos que han impulsado el turismo y a la influencia de los valores chinos en la actividad turística. En cuanto a al análisis del comportamiento del turista (grupo 2), las principales líneas de investigación son: los segmentos turísticos existentes; el comportamiento previo al viaje; el comportamiento en el destino; y los impactos que provoca la actividad turística en los turistas y los residentes. El último grupo de artículos analiza la industria turística (grupo 3) y estudia el fenómeno de los paquetes turísticos, los tours de tarifa reducida y aspectos relacionados con el desarrollo de la industria en un destino específico. En los siguientes apartados veremos cuáles han sido las aportaciones y resultados en cada una de las mencionadas áreas. Conviene mencionar que algunos artículos analizan el turismo chino explorando varios subgrupos temáticos, puesto que las líneas de investigación no son estancas y existe contacto entre ellas. 
Figura 4

MAPA CONCEPTUAL TEMÁTICO SOBRE LA INVESTIGACIÓN EN TURISMO CHINO



Fuente: elaboración propia. 


\section{RESULTADOS (2): LÍNEAS DE INVESTIGACIÓN}

\section{IV.1. Estudios sobre el contexto político y social}

\section{IV.1.1. Determinantes políticos y sociales}

El primer grupo de artículos examina cómo el contexto social y político de China da forma a este mercado turístico emisor y de qué manera la demanda de los turistas chinos se relaciona con los aspectos políticos, económicos y sociopolíticos del país (Guo et al., 2007; Dai et al., 2016). En estos estudios, los autores suelen sugerir líneas de actuación para agencias, gobierno y destinos. Tse y Hobson (2008), han tratado de encontrar los determinantes políticos y sociales que han dado forma al turismo chino y sus resultados muestran que las fuerzas que han impulsado el turismo son competitivas, demográficas, económicas, tecnológicas, culturales y políticas. Posteriormente, Mak (2013) ha analizado la influencia que ha tenido la ideología política en el desarrollo del turismo y destaca los cambios ocurridos a partir de la nueva era política al mando de Deng Xiaoping en 1976. Otro elemento propio del contexto chino es la entrada en vigor, en octubre de 2013, de la Ley sobre Turismo de China, con el objetivo de regular la práctica turística y aplicar un código de buenas prácticas. Ma et al. (2015) han estudiado las consecuencias de esta ley y señalan que tras su aprobación los turistas viajan con paquetes turísticos de mejor calidad pero de mayor precio, lo que disminuye el atractivo del viaje organizado a favor del viaje independiente.

\section{IV.1.2. Determinantes socioeconómicos y demográficos}

Diferentes autores han utilizado diversas aproximaciones para comprender los determinantes socioeconómicos del turismo chino emisor, que mayormente se dirige a los destinos asiáticos debido a la proximidad geográfica y la afinidad cultural (Xie y Li, 2009). Además, se relaciona la explosión del turismo chino con la emergencia de la clase media china y sus preferencias de consumo (Zeng y Go, 2013). Los resultados de estos estudios indican que hay distintos determinantes que definen al turista chino, en base al lugar de residencia, nivel de ingresos y nivel de educación. Además, la explotación de la encuesta china sobre hogares urbanos sugiere que los individuos realizan un gasto turístico en forma de «U» invertida a lo largo de su vida: el mayor gasto se produce entre los 35 y 45 años (Lin et al., 2015).

\section{IV.1.3. Valores chinos y su influencia en el turismo}

En este ámbito de estudio ha sido reconocido cómo los valores culturales chinos, el peso de la tradición confuciana y los conceptos de «cara» (mianzi o lian en chino) y de relaciones interpersonales (guanxi) influencian el comportamiento del turista (Hoare et al., 2011). «Cara», o apariencia, es un concepto vinculado al prestigio o autoestima social que un individuo quiere que los demás tengan de él en un contexto relacional. Guanxi se refiere al concepto de forjar contactos sociales para asegurarse favores en las relaciones personales futuras. Según Kwek y Lee (2010), la noción de harmonía domina el comportamiento del turista chino y se interrelaciona con el respeto por la autoridad, la intención de construir 
relaciones interpersonales provechosas y la conformidad con el grupo de viaje. Hsu y Huang (2016) han reconfigurado los valores chinos actuales y analizado sus implicaciones para el turismo. Los autores han identificado 40 ítems de valores y dan a conocer los valores chinos modernos: comodidad, indulgencia, ocio, liberación, intereses personales y ostentación. Además, comprender los valores chinos es crucial para entender las actitudes de los turistas de negocios (Kwek y Lee, 2015) y el comportamiento ante situaciones de discordancia en los destinos turísticos (Li et al., 2016).

\section{IV.2. Estudios sobre el comportamiento del turista}

\section{IV.2.1. Estudios sobre segmentos turísticos}

a) En función de las características de viaje

Es posible segmentar a los turistas chinos de acuerdo a las diferentes características del viaje: en función del gasto en el destino (Wang y Davidson, 2010); en base a las limitaciones para realizar la actividad turística (Li et al., 2011b); a las preferencias personales del turista (Zhang y Zhang, 2013); y a la pertenencia a diferentes subculturas chinas (chinos procedentes de China continental, Hong Kong, Taiwán, Macao o Singapur) (Kim et al., 2015). Estas posibles segmentaciones muestran que los turistas chinos son un grupo heterogéneo y que se debe diferenciar entre ellos. Hay diferentes formas de viaje y los más estudiados son los viajes en grupo (Group Package Tour), independiente (Free Independent Traveller), mochilero, de estudios y de negocios. Además, también existen distintos tipos de turistas en función del gasto en el destino, la edad, la región de origen, las limitaciones percibidas de viajar y las preferencias de viaje.

b) Estudios de segmentos minoritarios concretos

Las diferencias entre los tipos de turistas chinos han motivado que algunos investigadores se centren en explorar las características de segmentos concretos, como los turistas aventureros (Buckley et al., 2014; Gardiner y Kwek, 2016), los interesados en el turismo de auto-caravanas (Wu y Pearce, 2014a, 2014b; Wu, 2015), los interesados en cruceros (Fan y Hsu, 2014) y los turistas seniors (Lu et al., 2016; Wang et al., 2016b). También ha recibido especial atención el caso del turismo de juegos y el papel de los casinos en Macao. Los investigadores han tratado de comprender las motivaciones de los turistas (Wong y Rosenbaum, 2012), las diferencias de comportamiento entre diferentes grupos culturales chinos (Wan et al., 2013) y las percepciones de los turistas respecto a los servicios ofrecidos por los casinos (Lo et al., 2013). Estudios posteriores sobre Macao se han centrado en examinar las diferencias entre los turistas interesados en las apuestas y los que no (Zeng et al., 2014) y las relaciones entre experiencias de viaje y servicios ofrecidos (Wong y Li, 2015).

Un amplio número de investigadores han estudiado a los turistas jóvenes, tratando de conocer sus intereses particulares al elegir paquetes turísticos de viaje en grupo (Jin et al., 2014), la alta vinculación al Smartphone durante sus vacaciones (O’ Regan y Chang, 2015) y las diferencias de preferencias y expectativas respecto a los destinos (Prayag et al., 2015b; 
Park et al., 2016). Además, dentro del grupo de turistas jóvenes podemos diferenciar entre los que viajan en grupo, los independientes, mochileros y los estudiantes. Los mochileros chinos, también llamados Donkey Friends, son un grupo de turistas jóvenes que tienen diferentes preferencias de viaje (Ong y Du Cros, 2012; Chen et al., 2013), aunque su denominador común es el interés por la libertad de espíritu y la autorrealización (Chen y Weiler, 2014). Otro campo de estudio que ha despertado el interés es el comportamiento turístico de los jóvenes chinos que estudian fuera de su país (Shu y Scott, 2014) y protagonizan un modelo de turismo diferente que los estudiantes de otras nacionalidades, ya que en sus viajes están más interesados en la cultura y el patrimonio que en la diversión y el ocio (Xu et al., 2009; King y Gardiner, 2015). Además, estos estudiantes tienen un importante papel atrayendo más turistas y esparciendo comentarios positivos sobre el destino (Liu y Ryan, 2011; Chen et al., 2015)

\section{IV.2.2. Estudios sobre el comportamiento previo al viaje}

\section{a) Fuentes de información}

Los estudios sobre las fuentes de información nos muestran que en China la televisión es una importante fuente de información sobre los destinos (Sparks y Pan, 2009), junto a la gran relevancia de Internet (Choi et al., 2008). Además, estudios posteriores muestran que una diferencia muy destacable entre los turistas chinos y los norteamericanos recae en que los chinos confían de forma significativamente más elevada en el word-of-mouth que los norteamericanos (Kambele et al., 2015). Por último, Lu y Chen (2014) han señalado que los turistas chinos y japoneses muestran mayor confianza en los panfletos de las agencias de viaje que los turistas estadounidenses, aunque reconocen que el primer canal de información para chinos, japoneses y americanos es la información online.

\section{b) Elección del destino}

Los estudios sobre los factores relacionados con la elección de destino estudian por qué se elige un destino en vez de otro. Uno de los factores más influyentes en la elección es la familiaridad con el destino. En el caso de Taiwán, tener amigos, familiares o contactos procedentes de Taiwán o que ya hayan viajado allí es la variable que más afecta a la elección de destino y genera una imagen positiva del destino (Chen y Lin, 2012). Desde otro enfoque, Li et al. (2012) han estudiado el posicionamiento de EEUU en el mercado turístico emisor chino comparando este destino con Australia, Canadá, Francia, Reino Unido y Suiza. Estos autores indican que la promoción de los aspectos singulares de cada destino es la variable que más influye en la elección de destino. Lai et al. (2013) han utilizado al marco analítico del Modelo de Limitaciones en Ocio (Leisure Constraint Model) para examinar qué factores restringen el turismo chino a Estados Unidos. Por último, Andreu, Claver y Quer (2014) han explorado los atributos de Europa que se vinculan con la recepción de los turistas chinos mediante explotación de datos secundarios de la European Travel Commission y una muestra de 47 países europeos. Los resultados de estos estudios muestran que las percepciones de familiaridad, distancia cultural y riqueza patrimonial son elementos que están directamente relacionados con la elección del destino. 
c) Motivaciones y valores chinos

Varios investigadores se han centrado en estudiar las motivaciones turísticas relacionándolas con los valores culturales. Li y Cai (2012) han investigado la influencia de los valores personales y sus resultados muestran que estos tienen un efecto positivo en la motivación de viaje. Li et al. (2013) han analizado las motivaciones en base a la Grid-Group Cultural Theory para identificar tres tipos de perfiles culturales chinos (individualistas, jerárquicos e igualitaristas) y diez motivaciones principales. Las motivaciones de los turistas chinos pueden ser enmarcadas de acuerdo a los ideales confucianos y los resultados de esta línea de investigación muestran que el turismo es un instrumento para alcanzar el equilibrio en cinco dimensiones: la realización de uno mismo, la relación con la familia, la relación con contactos sociales, la relación con la sociedad y la relación con la naturaleza (Fu et al., 2015, 2016).

\section{d) Motivaciones hacia destinos concretos}

Varios artículos analizan las motivaciones y expectativas de los turistas chinos hacia destinos específicos y algunos de ellos comparan múltiples destinos (Yun y Joppe, 2011; Li et al., 2011c). Los estudios muestran que algunos destinos pueden asociarse a motivaciones principales, como en el caso Hong Kong y las motivaciones de compras (Li et al., 2011a; Tsang et al., 2014) y Macao y las motivaciones de juego y apuestas (Park et al., 2015). Los estudios de las motivaciones hacia destinos específicos sugieren que diferentes destinos tienen diferentes elementos que atraen a los turistas y diferentes ítems motivacionales asociados. Algunos investigadores han analizado las motivaciones para viajar a destinos occidentales, como es el caso de los estudios sobre Canadá (Lu, 2011); Estados Unidos (Hua y Yoo, 2011); Hawái (Johanson, 2008; Agrusa et al., 2011); Nueva Zelanda (Mohsin, 2008); Australia (Chow y Murphy, 2011); Europa Occidental en general (Prayag et al., 2015a; Zhu et al., 2015); Grecia (Assiouras et al., 2014), Italia (Corigliano, 2011) y el festival Oktoberfest en Alemania (Yang et al., 2011). Entre estos estudios sobresale el uso del modelo Push and Pull (aunque no es el único empleado) que permite dividir las motivaciones entre los elementos que empujan al viajero a viajar y los elementos del destino que atraen el viaje. Estas investigaciones suelen utilizar categorías motivacionales existentes y enfoques cuantitativos. Las categorías más empleadas para estudiar las motivaciones son: relajarse, ocio y compras, visitar lugares icónicos, la cultura y patrimonio local y la naturaleza y el patrimonio ecológico.

\section{e) Imágenes del destino}

Otro campo de investigación de especial interés para los académicos es comprender las imágenes proyectadas y percibidas de los destinos turísticos. Diferentes artículos examinan la imagen de Taiwán como destino mediante diferentes aproximaciones: analizando las imágenes en revistas de viajes y comparándolo con otros destinos (Hsu y Song, 2012); mediante el método de la libre elicitación (Lin et al., 2012); comparando la imagen percibida con la proyectada (Song y Hsu, 2013); y examinando con qué elementos se asocia la marca Taiwán entre potenciales turistas (Huang et al., 2015). Los estudios de las imágenes turísticas en destinos que no pertenecen a la zona asiática son numerosos y se han investigado diferentes 
casos. Los estudios sobre la imagen de Australia muestran las diferencias entre chinos procedentes de la China continental y chinos procedentes de Singapur (Kwek y Lee, 2008) y los iconos más destacados del país (Huang y Gross, 2010). En el caso de Nueva Zelanda, los estudios sugieren que en este destino tiene una gran importancia la imagen de espacio ecológico muy protegido (Sun et al., 2014), además de las actividades en el exterior, desarrollo y modernidad y la subsistencia de elementos de la cultura «pakeha» (Sun et al., 2015). En EEUU predominan las imágenes de espacio urbano, desarrollo económico, sistema democrático, alto desarrollo tecnológico y las grandes ciudades de la costa este y la costa oeste (Li y Stepchenkova, 2012; Stepchenkova y Li, 2012). En cuanto a Europa, principalmente las imágenes están conformadas por elementos arquitectónicos y patrimoniales (Aramberri y Liang, 2012).

\section{IV.2.3. Estudios sobre el comportamiento y la experiencia en el destino}

a) Actividades en el destino

No hay demasiados estudios sobre el comportamiento del turista en el destino aunque se ha diferenciado entre aquellos que examinan las actividades preferidas de los turistas y los estudios que analizan las preferencias gastronómicas. Se han estudiado las preferencias de actividades en Australia (Chow y Murphy, 2008) y los resultados muestran que los turistas prefieren: la comida, visitas a sitios de interés, el patrimonio y la cultura, actividades participativas, entretenimiento y compras. Posteriormente, Liang et al. (2015) estudian las diferencias de comportamiento de los turistas chinos en sus viajes a Macao en una evolución temporal de tres años seguidos: 2011, 2012 y 2013. Los resultados confirman la tendencia de que las preferencias del turista chino en Macao están evolucionando: han aumentado significativamente el número de turistas que se auto-organizan el viaje en grupos reducidos y se reduce el interés en el juego y las apuestas a favor de otras actividades.

b) Gastronomía, restaurantes y alojamiento en el destino

Algunos investigadores han tratado de comprender las preferencias gastronómicas de los turistas en destinos concretos. Lin y Chen (2012) evalúan las necesidades gastronómicas de los turistas chinos en Taiwán y los resultados muestran que los turistas agradecen verse involucrados en actividades relacionadas con la comida local, elemento que está vinculado con la intención de revisitar y recomendar el destino. Law et al. (2008) estudian las percepciones de importancia respecto a diversos atributos relacionados con los servicios presentes en los restaurantes en Taiwán y los resultados señalan que los turistas prefieren una buena actitud del personal del restaurante, mayor apariencia de higiene y más rapidez de atención. Por último, Chang et al. (2010) estudian las preferencias gastronómicas de los turistas chinos en Australia. Estos autores comprueban que el modelo de la experiencia en el destino se compone de: comida china (que es el centro de la experiencia), comida local (para explorar nuevos gustos y que el viaje sea más auténtico) y poca exigencia culinaria (para no perturbar la harmonía del grupo de viaje y conformarse con las sugerencias del guía de grupo). 


\section{IV.2.4. Estudios sobre los impactos de la actividad turística}

a) Impactos en el turista: satisfacción con el destino

Estudiar la satisfacción en destino es utilizado por los académicos como una herramienta para saber qué aspectos de la experiencia y el servicio ofrecido deben ser mejorados para aumentar la fidelidad. En este sentido, la fidelidad es la intención de revisitar el mismo destino y también la intención de diseminar comentarios positivos entre conocidos y/o en plataformas online. Con esta perspectiva, algunos investigadores han examinado qué elementos otorgan una mayor y una menor satisfacción en diferentes destinos. Se ha estudiado los atributos de Vietnam en relación a la satisfacción (Truong y King, 2009). Se han explorado las motivaciones culturales y la autenticidad percibida en relación a la satisfacción en Hong Kong (Nguyen y Cheung, 2016) y también el impacto de los servicios turísticos con la satisfacción en el contexto de Hong Kong (Chan et al., 2015). También se han estudiado las motivaciones y satisfacción de los turistas chinos en relación al viaje a Corea del Norte (Li y Ryan, 2015). Algunos investigadores han tratado de examinar la relación causal entre las expectativas turísticas, las motivaciones de viaje, la calidad del tour, las quejas y la fidelidad de los turistas hacia el destino en Corea del Sur (Lee et al., 2011) y en Australia (Mao y Zhang, 2014). Por último, se han analizado las preferencias y satisfacciones de los turistas chinos con las actividades de compras en Estados Unidos de América (Xu y McGehee, 2012).

b) Impactos en el turista: aprendizaje

Pearce y Lu (2011) tratan de crear un marco de estudio de los resultados de aprendizaje obtenidos de la actividad turística de los viajeros chinos de grupos organizados mediante una revisión de la literatura sobre aprendizaje, turismo y turismo de grupo. Posteriormente, Tse (2014) se pregunta en qué sentido el turismo mejora la calidad de vida, la dirección vital y la percepción de uno mismo a largo plazo. Sus resultados sugieren que hay cambios positivos en la percepción de la vida entre los viajeros, comparado con el grupo de control que no realizan viajes. Los viajeros se sienten más positivos en su actitud hacia la vida, sentido de control y perspectivas. Posteriores estudios parecen indicar que el turismo no tiene únicamente impactos a nivel individual sino que también mejora la comprensión y la relación entre territorios: Ji et al. (2016) estudian las percepciones emocionales de los turistas chinos en su viaje por Japón y sus resultados muestran que el viaje ayuda a desafiar y superar los estereotipos sobre Japón. De modo parecido, Rowen (2014) y Qiu et al. (2015) estudian los impactos de la apertura turística de China en su relación con Taiwán. Estos autores concluyen que la actividad turística es beneficiosa para construir una relación pacífica y de mutuo reconocimiento, aunque también se genera una relación territorial de dominancia entre potencias geopolíticas.

\section{c) Impactos en la comunidad local}

El turismo chino ha generado un gran volumen de flujos turísticos y en algunos destinos su visita genera reacciones discordantes entre la comunidad local. Hong Kong es el primer destino para los turistas procedentes de China continental en número de llegadas y en 2014 
lo visitaron cerca de 40 millones de turistas (UNWTO, 2015). La explosión del turismo chino ha generado un influjo sin precedentes de turismo hacia Hong Kong y ha producido un cambio tremendo en la industria turística, la economía y la comunidad local hongkonesa. Varios investigadores han estudiado las percepciones locales respecto al turismo chino y ponen de manifiesto que existe un malestar entre la comunidad local (Yeung y Leung, 2007; Siu et al., 2013; Loi y Pearce, 2015). De forma diferente, Breakey et al. (2008) han estudiado el impacto del turismo chino en Australia y lo comparan con el boom del turismo japonés que ocurrió dos décadas antes. Después de analizar el desarrollo de Australia como destino turístico, concluyen que en este territorio el turismo chino genera un impacto positivo y que el país debe prepararse adecuadamente para recibir a estos turistas.

\section{IV.3. Estudios sobre la industria turística}

\section{IV.3.1. Tours de tarifa reducida}

En la línea de investigación de la industria turística un gran número de investigadores han tratado de comprender los llamados «Paquetes turísticos de tarifa reducida», o Zero-Fare Tour. Estos paquetes se refieren a productos turísticos para viajes en grupo de muy bajo coste, donde los operadores obtienen beneficios procedentes de comisiones de compras en los destinos. Para que el negocio sea provechoso, el guía debe forzar a los turistas a comprar productos de baja calidad a altos precios, lo que conlleva situaciones de elevada tensión y malestar entre los turistas (Zhang et al., 2009a, 2009b). Estas prácticas han sido estudiadas como fenómenos poco éticos que aparecen debido a la concentración de poder en los operadores mayoristas, la competición de precios entre los operadores minoristas y una visión de obtener beneficios a corto plazo (King et al., 2006), lo que provoca una mala imagen del destino turístico y bajos niveles de satisfacción (March, 2008). A este respecto, Tse y Tse (2015) han analizado las aproximaciones de los gobiernos de la República Popular China y de Hong Kong para mejorar estos productos y los autores explican cómo ambos gobiernos han seguido diferentes enfoques.

\section{IV.3.2. Paquetes turísticos de viaje en grupos organizados}

Otro elemento de la industria turística que ha captado la atención de los investigadores es el fenómeno de los viajes en grupos organizados y su prevalencia como forma de viaje. Chang et al. (2007) han estudiado las diferencias en los estadios de desarrollo de los paquetes turísticos ofrecidos por la industria turística de China y Taiwán. Chen et al. (2016b) han examinado la evolución de la demanda del turismo chino en Hong Kong y la influencia de los paquetes turísticos de viajes organizados sobre el comportamiento turístico. Los resultados muestran que los viajes en grupo ofrecen ventajas de precio para el consumidor pero dificultan la satisfacción y la intención de repetir el viaje.

\section{IV.3.3. El desarrollo de la industria en destinos concretos}

También ha despertado interés entre los académicos el estudio de las características del desarrollo de la industria turística en destinos concretos. Zhang y Murphy (2009) estudian 
el caso de Goldfields Region, en Victoria (Australia) para ver las estrategias de marketing e identifican discrepancias entre las actitudes de los agentes de viaje y los proveedores de servicios. Sausmarez et al. (2012) han explorado la relación entre los turoperadores chinos y los británicos en relación al turismo chino en el Reino Unido. Los resultados muestran que los turoperadores ingleses consideran que es difícil adecuarse a las preferencias gastronómicas de alojamiento y culturales de los turistas chinos.

\section{IV.4. Metodologías propuestas}

El turismo chino se ha estudiado mayoritariamente mediante constructos y paradigmas occidentales, que son los dominantes en el actual estudio del turismo como ciencia social. Ante esta actitud, Zhang y Shelton (2015) han criticado el panorama actual y proponen que se utilicen nuevos enfoques para estudiar el turismo chino que se dirige a Nueva Zelanda. Anteriormente, algunos autores habían contribuido mediante nuevas aportaciones teóricas y empíricas a la creación de otras opciones metodológicas. Jiang et al. (2012) han comprobado que las motivaciones turísticas se han estudiado en numerosas ocasiones mediante el modelo Push and Pull y proponen utilizar la Cadena de medios y fines (Mean-end chain) en base a tres dimensiones: valores, consecuencias y atributos. Hsu y Huang (2012) han propuesto una extensión del Modelo del Comportamiento Planificado y lo han probado mediante los datos extraídos en 311 encuestas entre turistas chinos. Wang et al. (2016a) han tratado de construir y probar un modelo teórico sobre la formación de expectativas entre los modelos y la diferencia de género. Por último, Chen et al. (2016a) han diseñado un modelo para extraer directamente el contenido semántico de los blogs chinos y obtener conclusiones sobre la valoración de los destinos.

\section{SÍNTESIS Y POSIBLES AREAS DE INVESTIGACIÓN FUTURAS}

\section{V.1. Síntesis integrada de resultados}

Aproximadamente el 33\% de los artículos analizados se asientan sobre estudios que no analizan ningún destino en particular sino que tratan de comprender las características transversales del turismo chino emisor. En estos artículos se trata de comprender el contexto político y económico chino, la legislación sobre turismo, los determinantes socioeconómicos del turismo y las características demográficas de la población. También hay aportaciones sobre el comportamiento del turista de acuerdo a los valores chinos tradicionales y contemporáneos, las motivaciones en relación a los elementos culturales chinos y los impactos del turismo en la sociedad china. Por último, estos artículos también han analizado aspectos de la industria turística y han propuesto metodologías y modelos de estudio del turismo. Estas aportaciones permiten generar un macro-contexto que define las características intrínsecas de este mercado emisor. La presente revisión de la literatura permite comprender que el mercado emisor chino está en evolución y en una primera fase de crecimiento, por lo que algunos de los resultados no son estáticos y variarán de acuerdo a los cambios que se están produciendo en China en la actualidad. A modo de ejemplo, podemos percibir algunos de los patrones de cambio en las dinámicas turísticas: poco a poco aumenta el interés en los viajes 
independientes; aumenta la madurez de algunos turistas que en muchas ocasiones ya han visitado varios destinos y prefieren sumergirse más en la cultura local en sus viajes; y en los últimos años se han identificado un creciente número de segmentos turísticos con diferentes preferencias, motivaciones y expectativas de viaje.

El presente estado de la cuestión ha puesto de manifiesto que existe una gran comunidad de investigadores que tratan de comprender el turismo chino en destinos concretos, puesto que aproximadamente el $67 \%$ de los artículos están asentados sobre estudios de caso. Estos estudios de caso sirven tanto para explicar el fenómeno del turismo chino en ese destino en particular, como para tratar de extraer conclusiones más generales que se pueden extrapolar a diversos destinos. Los estudios de caso tratan de conocer el perfil del turista, los factores que causan el viaje, las experiencias en el lugar, los resultados de la actividad turística y probar nuevos modelos y propuestas metodológicas. Según los artículos analizados, los investigadores se han interesado en un primer lugar por la experiencia previa al viaje, explorando fuentes de información, factores de elección de destino, motivaciones e imágenes turísticas. En segundo lugar, se han estudiado las experiencias en el destino, de las que destacan las compras, actividades y cuestiones de restauración y alojamiento. En tercer lugar, se han desarrollado estudios sobre los impactos del turismo: la satisfacción con el viaje, el aprendizaje y los impactos en la comunidad local. Por último, algunos investigadores se han preocupado por comprender rasgos de la industria turística en el destino. En el presente trabajo hemos visto que no en todos los destinos se han estudiado todos los elementos. Por ejemplo, los impactos sobre la comunidad local se han concentrado en investigaciones relativas a Hong Kong que reciben un mayor número de turistas y su presencia provoca reacciones negativas entre los residentes. Los estudios de caso son circunstanciales y permiten comprender el turismo chino en destinos concretos, aunque debemos tener en cuenta que el comportamiento del turista chino y las imágenes e industria del destino están en evolución y los resultados

Figura 5

SÍNTESIS INTEGRADA: MACRO CONTEXTO Y ESTUDIOS DE CASO

\begin{tabular}{|l|l|}
\hline \multicolumn{1}{|c|}{ MACRO-CONTEXTO } & \multicolumn{1}{c|}{ ESTUDIOS DE CASO } \\
\hline - Determinantes políticos & - Segmentos turísticos \\
- Determinantes socio-económicos & - Fuentes de información \\
- Factores demográficos & - Elección de destino \\
- Valores tradicionales y contemporáneos & - Motivaciones \\
- Segmentaciones de turistas & - Experiencias y preferencias en el destino \\
- Impactos del turismo (aprendizaje) & - Satisfacción del viaje \\
- Características de la industria china & - Aprendizaje del turista \\
\hline
\end{tabular}

Fuente: elaboración propia. 
podrían limitarse a un periodo de tiempo concreto. En la figura 5 podemos ver los resultados de la síntesis integrada dividiendo entre los artículos que generan el macro-contexto chino y los artículos que se centran en el estudio respecto al destino.

\section{V.2. Posibles áreas de investigación futuras planteadas desde la perspectiva geográfica}

El turismo es una campo de investigación multidisciplinar y el conocimiento en turismo se deriva de disciplinas tales como la geografía, la sociología, psicología, economía, ciencias políticas y filosofía, entre otras (Tribe y Liburd, 2016; Benckendorff y Zehrer, 2013). La geografía del turismo se preocupa de forma central de las relaciones entre la actividad turística y el espacio y el entorno humano y natural en el que se desarrolla esta actividad (Williams y Lew, 2015). La geografía del turismo ayuda a entender el turismo como un fenómeno binario en relación entre humano/físico y conocimiento aplicado/teórico (Michael Hall, 2013), prestando especial atención a la gestión turística (Hall y Page, 2009). El presente estudio nos permite revelar que ninguno de los artículos revisados han utilizado marcos conceptuales propios de la geografía o de la geografía del turismo. Además, previas revisiones de la literatura sobre turismo chino emisor han notado la ausencia de trabajos con un enfoque procedente de la geografía (Jin y Wang, 2016). Después de analizar los artículos publicados en los últimos diez años, tratamos de ofrecer a continuación posibles áreas de investigación teniendo en cuenta la perspectiva geográfica para suplir estas deficiencias.

En primer lugar, conviene señalar que los destinos sobre los que se ha estudiado el turismo chino emisor son muy variados pero encontramos algunas áreas asusentes de estudio. Los países más analizados son Australia, Macao, Estados Unidos, Hong Kong y Taiwán y las regiones más estudiadas son Asia, Oceanía, América y Europa por este orden. Conviene entender que hay una escasa relación entre los destino estudiados y los que atraen más turismo chino. Varios informes de investigación han señalado que los destinos a los que se dirige el turista chino están en primer lugar en Asia, seguido de Europa, América, Oceanía y África (Ipsos, 2016; The Wall Street Journal, 2015), aunque donde se produce mayor gasto es en Estados Unidos, Europa y Japón. Estas consideraciones nos permiten señalar que los países europeos han sido poco estudiados y que se debe prestar mayor atención al fenómeno del turismo chino en este continente. Consideramos que sería interesante que se desarrollaran estudios sobre el turismo chino en los países europeos. Francia y España son países con alto éxito turístico a nivel mundial y en 2015 se situaron respectivamente primero y tercero en el ranking mundial de visitas turísticas, aunque apenas se han desarrollado estudios sobre el turismo chino en estos países. Del mismo modo, Japón es un destino que ha sido muy poco estudiado pese a que es uno de los destinos más visitados por los turistas chinos.

Otro de los aspectos que interesa comprender desde la geografía del turismo es cómo se distribuye la actividad turística por el territorio en un destino turístico. De los 124 artículos analizados únicamente dos de ellos ofrecen resultados sobre la distribución geográfica del turismo chino en el destino, mientras que en todos los demás artículos se omite este elemento. Li y Stepchenkova (2012) han trazado un mapa de Estados Unidos y los niveles de consciencia del territorio estadunidense según potenciales turistas chinos. Ryan y $\mathrm{Gu}$ (2007) trataron de comprender cómo los turistas chinos planificaban su tiempo recorriendo itinerarios en California (Estados Unidos) y sus resultados muestran la dispersión y concen- 
tración de los recorridos preferidos de los potenciales turistas chinos. La presente revisión de la literatura sobre turismo chino nos permite afirmar que los recorridos, los itinerarios y la distribución geográfica del turismo chino en destino son una laguna de investigación. Sugerimos que futuros estudios podrían tratar de esclarecer cómo se reparte el turismo chino en los territorios de destino. La distribución geográfica del turismo es un factor clave para entender la distribución de beneficios de la actividad turística y es un aspecto del turismo chino que puede ser estudiado con profundidad para poder orientar la gestión turística en el destino (Lojo, 2016)

Por último, también ha sido escasamente estudiada la cuestión de la autenticidad percibida y consumida respecto al patrimonio cultural de los destinos donde se desplaza el turismo chino (Nguyen y Cheung, 2016). Los lugares y sus imágenes son fundamentales en la práctica turística. La demanda turística emana de percepciones individuales y colectivas sobre lugares particulares (Williams y Lew, 2015). Desde la geografía del turismo se puede tratar de entender cómo el turista chino se ve afectado por constructos culturales sobre el destino, la tematización del paisaje urbano, los espacios patrimoniales y culturales y la relación entre autenticidad, patrimonio y cultura. Todos estos aspectos no han sido desarrollados en la investigación sobre turismo chino emisor y pueden contribuir a entender este mercado emisor y a gestionar los destinos.

\section{DISCUSIÓN}

Los resultados muestran que en los recientes años han sido publicados numerosos artículos sobre el turismo chino internacional y reconocen las principales corrientes de investigación aparecidas en los últimos diez años en base a una síntesis temática. A partir de las lagunas en la investigación analizada y mediante la perspectiva geográfica, sugerimos posibles futuras áreas de investigación sobre aspectos que no han sido todavía desarrollados. Europa es uno de los destinos de larga distancia principales para el turismo chino e identificamos en este continente algunos destinos que no han sido apenas estudiados. Además, los itinerarios y la distribución del turismo chino en los destino es un nuevo campo de estudio que puede proveer resultados útiles para la gestión y la comprensión del turismo chino. Por último, también proponemos como novedoso campo de estudio las indagaciones sobre las relaciones entre los constructos sociales de los turistas, los destinos y el patrimonio cultural.

Para alcanzar estos resultados hemos seleccionado los artículos relativos al turismo chino emisor de los últimos 10 años publicados en 16 revistas académicas de impacto. Únicamente hemos extraído artículos de publicaciones en inglés, lo que puede limitar esta investigación y producir un cierto sesgo en los resultados. De todos modos, como hemos indicado en el apartado metodológico, las revistas consideradas como fuentes de información son de reconocida relevancia en la investigación en turismo en el panorama Occidental y figuran en varios rankings científicos. Cabe añadir que esta revisión de la literatura se ha realizado bajo una visión occidental y se estudia el turismo chino desde un punto de vista exterior (ético) y quizás los investigadores orientales pueden aportar un punto de vista complementario (émico). Los materiales del presente estudio han sido 124 artículos y se han clasificado temáticamente. Esta clasificación ha sido construida sobre la base del marco conceptual de la ciencia turística de Leiper (1979) y del comportamiento turístico de Pearce (2006), aunque en los 
resultados se ha desarrollado un esquema conceptual propio con las áreas temáticas que han surgido a través de la técnica de análisis de contenidos. Este planteamiento ofrece unos resultados distintos a las anteriores revisiones de la literatura sobre turismo chino y contribuye al conocimiento académico con un nuevo punto de vista y una nueva clasificación temática. Li et al. (2008) revisaron 30 artículos y sus resultados indican que los primeros estudios sobre turismo chino se concentraron en comprender el fenómeno en los destinos de Hong Kong, Australia, Estados Unidos, Singapur y Corea del Sur. En el presente estudio comprobamos que los destinos estudiados han aumentado, aunque falta profundizar en algunas regiones. Por último, señalamos importantes lagunas de la investigación gracias a aplicar la perspectiva geográfica, que no había sido aplicada previamente. Este punto de vista puede ser complementado con el de otros autores que consideran que en la agenda de investigación sobre el turismo chino falta incluir nuevas metodologías y paradigmas que no sean los occidentales para comprender las particularidades del mercado chino (Cai et al., 2008; Jin y Wang, 2016).

\section{CONCLUSIONES}

En el presente artículo hemos identificado las áreas de estudio existentes en la investigación sobre turismo chino emisor siguiendo una revisión sistemática para ofrecer un estado actual de la cuestión. Hemos visto que los esfuerzos en la investigación sobre turismo chino han contribuido sustancialmente al conocimiento de este turismo y se han enfocado en entender el contexto turístico, el comportamiento del turista y la industria turística. Los investigadores han considerado relevante entender las dinámicas de este mercado emisor, el posicionamiento de los destinos y también los impactos que produce este turismo entre la comunidad local. En función de si son estudios generales o aplicados a un destino concreto, los artículos investigan el macro-contexto, estudios de caso sobre destino y propuestas teórico/metodológicas. Además, el elevado número de aportaciones sobre este tema nos informa de que es un campo de investigación fértil que ha despertado el interés de la academia. La distribución temporal de las publicaciones indica que estamos ante un tema de importancia creciente. Los resultados sugieren que la gestión del turismo chino implica conocer el contexto chino y el comportamiento del turista para procurar un desarrollo satisfactorio de la actividad para los turistas y sostenible para los destinos y sus residentes.

Por último, hemos comprobado que la perspectiva geográfica está prácticamente ausente en la investigación existente sobre turismo chino emisor. Hemos visto que Europa y Japón son áreas muy poco estudiadas en relación al elevado número de turistas chinos que atraen. Además, hemos propuesto futuras áreas de investigación que se dirijan a entender las relaciones entre los espacios geográficos, las construcciones sociales y la cultura. Del mismo modo, comprender itinerarios, recorridos y paradas de los turistas por el territorio puede ayudar a gestionar el turismo chino de forma más sostenible y mejorar el conocimiento sobre este mercado emisor. De este modo y de forma complementaria a los objetivos de la investigación, en el presente estudio hemos puesto de manifiesto que el turismo se estudia desde un amplio número de disciplinas científicas y que la investigación sobre turismo chino puede desarrollarse aplicando la perspectiva geográfica, ya que apenas ha sido considerada anteriormente. 


\section{REFERENCIAS BIBLIOGRÁFICAS}

AGRUSA, J., KIM, S.S. y WANG, K.-C. (2011): «Mainland Chinese Tourists to Hawaii: Their Characteristics and Preferences». Journal of Travel \& Tourism Marketing, vol. 28, no 3, 261-278.

ANDREU, R., CLAVER, E. y QUER, D. (2014): «Destination Attributes and Chinese Outbound Tourism to Europe». Journal of China Tourism Research, vol. 10, n 3, 275-291.

ARAMBERRI, J. y LIANG, C. (2012): «The Chinese Gaze: Imaging Europe in Travel Magazines». Journal of China Tourism Research, $\mathrm{n}^{\circ}$ 8, 284-301.

ASSIOURAS, I., SKOURTIS, G., KONIORDOS, M. y GIANNOPOULOS, A.A. (2014): «Segmenting East Asian Tourists to Greece by Travel Motivation». Asia Pacific Journal of Tourism Research, vol. 20, $\mathrm{n}^{\circ}$ 12, 1-22.

BENCKENDORFF, P. y ZEHRER, A. (2013): «A network analysis of tourism research». Annals of Tourism Research, vol. 43, 121-149.

BOOTH, A., PAPAIOANNOU, D. y SUTTON, A. (2012): Systematic approaches to a successful literature review. Thousand Oaks, CA, Sage.

BREAKEY, N., DING, P. y LEE, T. (2008): «Impact of Chinese Outbound Tourism to Australia: Reviewing the Past; Implications for the Future». Current Issues in Tourism, vol. $11, \mathrm{n}^{\circ} 6,587-603$.

BRINER, R.B. y DENYER, D. (2012): «Systematic Review and Evidence Synthesis as a Practice and Scholarship Tool» en The Oxford Handbook of Evidence-Based Management (ed. D. M. Rousseau). New York, Oxford University Press Inc., 112-129.

BUCKLEY, R., MCDONALD, K., DUAN, L., SUN, L. y CHEN, L.X. (2014): «Chinese model for mass adventure tourism». Tourism Management, vol. 44, 5-13.

CAI, L., LI, M. y KNUTSON, B.J. (2008): «Research on China Outbound Market: A MetaReview». Journal of Hospitality \& Leisure Marketing, vol. 16, nº 1, 5-20.

CALLAHAN, J.L. (2014): «Writing Literature Reviews: A Reprise and Update». Human Resource Development Review, vol. 13, n 3, 271-275.

CHAN, A., HSU, C.H.C. y BAUM, T. (2015): «The Impact of Tour Service Performance on Tourist Satisfaction and Behavioral Intentions: A Study of Chinese Tourists in Hong Kong». Journal of Travel \& Tourism Marketing, $\mathrm{n}^{\circ}$ 32, 18-33.

CHANG, J., WANG, K.-C., GUO, Y., SU, C.J. y YEN, S.J. (2007): «Trends in outbound group package tours in China and Taiwan: a marketing mix perspective». Tourism Analysis, vol. 12, 257-270.

CHANG, R.C.Y., KIVELA, J. y MAK, A.H.N. (2010): «Food preferences of Chinese tourists». Annals of Tourism Research, vol. 37, nº 4, 989-1011.

CHEN, C.-C. y LIN, Y.-H. (2012): «Segmenting Mainland Chinese Tourists to Taiwan by Destination Familiarity: a Factor-cluster Approach». International Journal of Tourism Research, vol. 14, 339-352.

CHEN, F.-W., GUEVARA, A. y ALARCÓN, P. (2016a): «Automatically extracting tourismrelated opinion from Chinese social media». Current Issues in Tourism, 1-18.

CHEN, G., BAO, J. y HUANG, S. (Sam) (2013): «Segmenting Chinese Backpackers by Travel Motivations». International Journal of Tourism Research, vol. 16, 355-367. 
CHEN, H. y WEILER, B. (2014): «Chinese Donkey Friends in Tibet - Evidence from the Cyberspace Community». Journal of China Tourism Research, vol. 10, n 4, 475-492.

CHEN, N., DWYER, L. y FIRTH, T. (2015): «Factors Influencing Chinese Students' Behavior in Promoting Australia as a Destination for Chinese Outbound Travel». Journal of Travel and Tourism Marketing, vol. 32, 366-381.

CHEN, Y., SCHUCKERT, M., SONG, H. y CHON, K. (2016b): «Why Can Package Tours Hurt Tourists? Evidence from China's Tourism Demand in Hong Kong». Journal of Travel Research, vol. 55 , $\mathrm{n}^{\circ} 4,427-439$.

CHINADAILY (2015): «France welcomes record number of Chinese visitors in 2015». ChinaDaily Europe. Disponible en: http://europe.chinadaily.com.cn/business/2015-08/22/ content_21671709.htm [Consulta: 22 de junio de 2016].

CHOI, S., LEHTO, X. y MORRISON, A.M. (2008): «Segmenting Chinese Visitors to Macau by Information Source Variables». Journal of Hospitality \& Leisure Marketing, vol. 16, $n^{\circ} 1-2,81-104$.

CHOW, I. y MURPHY, P. (2008): «Travel Activity Preferences of Chinese Outbound Tourists for Overseas Destinations». Journal of Hospitality Marketing \& Management, vol. $16, \mathrm{n}^{\circ} 1,61-80$.

CHOW, I. y MURPHY, P. (2011): «Predicting Intended and Actual Travel Behaviors: An Examination of Chinese Outbound Tourists to Australia». Journal of Travel \& Tourism Marketing, vol. 28, $\mathrm{n}^{\circ}$ 3, 318-330.

CORIGLIANO, M.A. (2011): «The Outbound Chinese Tourism to Italy: The New Graduates' Generation». Journal of China Tourism Research, vol. 7, nº 4, 396-410.

DAI, B., JIANG, Y., YANG, L. y MA, Y. (2016): «China's outbound tourism - Stages, policies and choices». Tourism Management, 1-6.

DENYER, D. y TRANFIELD, D. (2009): «Producing a systematic review» en The SAGE Handbook of organizational research methods (eds. D. A. Buchanan y A. Bryman). London, Sage Publications, 671-689.

FAN, D.X.F. y HSU, C.H.C. (2014): «Potential Mainland Chinese Cruise Travelers' Expectations, Motivations, and Intentions». Journal of Travel \& Tourism Marketing, vol. 31, $\mathrm{n}^{\circ} 4,522-535$.

FARINÓS, J. (2008): «Gobernanza territorial para el Desarrollo Sostenible : Estado de la Cuestión y Agenda.» Boletín de la Asociación de Geógrafos Españoles, n 46, 11-32.

FU, X., CAI, L. y LEHTO, X. (2015): «A Confucian Analysis of Chinese Tourists' Motivations». Journal of Travel \& Tourism Marketing, vol. 32, n 3, 180-198.

FU, X., CAI, L. y LEHTO, X. (2016): «Framing Chinese Tourist Motivations Through the Lenses of Confucianism». Journal of Travel \& Tourism Marketing.

GARDINER, S. y KWEK, A. (2016): «Chinese Participation in Adventure Tourism: A Study of Generation Y International Students' Perceptions». Journal of Travel Research,

GARZA-REYES, J.A. (2015): «Lean and Green - A systematic review of the state of the art literature». Journal of Cleaner Production, vol. 102, 18-29.

GUO, Y., KIM, S.S. y TIMOTHY, D.J. (2007): «Development Characteristics and Implications of Mainland Chinese Outbound Tourism». Asia Pacific Journal of Tourism Research, vol. 12, n 4, 313-332. 
HALL, C.M. y PAGE, S.J. (2009): «Progress in Tourism Management: From the geography of tourism to geographies of tourism - A review». Tourism Management, vol. 30, $\mathrm{n}^{\circ} 1$, 3-16.

HOARE, R.J., BUTCHER, K. y O'BRIEN, D. (2011): «Understanding Chinese Diners in an Overseas Context: A Cultural Perspective». Journal of Hospitality \& Tourism Research, vol. $35, \mathrm{n}^{\circ} 3,358-380$.

HSU, C.H.C. y HUANG, S. (Sam) (2012): «An Extension of the Theory of Planned Behavior Model for Tourists». Journal of Hospitality \& Tourism Research, vol. 36, n 3, 390-417.

HSU, C.H.C. y HUANG, S. (Sam) (2016): «Reconfiguring Chinese cultural values and their tourism implications». Tourism Management, vol. 54, 230-242.

HSU, C.H.C. y SONG, H. (2012): «Projected Images of Major Chinese Outbound Destinations». Asia Pacific Journal of Tourism Research, vol. 17, nº 5, 577-593.

HUA, Y. y YOO, J.J.-E. (2011): «Travel Motivations of Mainland Chinese Travelers to the United States». Journal of China Tourism Research, vol. 7, nº 4, 355-376.

HUANG, S. (Sam) y GROSS, M.J. (2010): «Australia's Destination Image Among Mainland Chinese Travelers: an Exploratory Study». Journal of Travel \& Tourism Marketing, vol. $27, \mathrm{n}^{\circ} 1,63-81$.

HUANG, Z. (Joy), LI, M. y LI, Q. (2015): «An Examination of Taiwan Destination Brand Associations: From the Perspective of Mainland Chinese Tourists». Journal of Travel \& Tourism Marketing, vol. 32, 50-64.

INE (2016): «Movimientos Turísticos en Frontera». Instituto Nacional de Estadística. Disponible en: http://www.ine.es/daco/daco42/frontur/frontur_total15.xlsx [Consulta: 16 de mayo de 2016].

IPSOS (2016): «Market Research Report on Chinese Outbound Tourist (City) Consumption 2015». Ipsos. Disponible en: http://www.ipsos.com.cn/sites/default/files/01.2016en_travel.pdf [Consulta: 14 de mayo de 2016].

JI, M., LI, M. y HSU, C.H.C. (2016): «Emotional Encounters of Chinese Tourists to Japan». Journal of Travel \& Tourism Marketing, vol. 33, $\mathrm{n}^{\circ}$ 5, 645-657.

JIANG, S., SCOTT, N., DING, P. y ZOU, T.T. (2012): «Exploring Chinese Outbound Tourism Motivation Using Means-End Chains: A Conceptual Model». Journal of China Tourism Research, vol. 8, n 4, 359-372.

JIN, T., LIN, V.S. y HUNG, K. (2014): «China's Generation Y's Expectation on Outbound Group Package Tour». Asia Pacific Journal of Tourism Research, vol. 19, n 6, 617-644.

JIN, X. y WANG, Y. (2016): «Chinese Outbound Tourism Research: A Review». Journal of Travel Research, vol. 55, n 4, 440-453.

JOHANSON, M. (2008): «The Outbound Mainland China Market to the United States: Uncovering Motivations for Future Travel to Hawaii». Journal of Hospitality Marketing \& Management, vol. 16, $\mathrm{n}^{\circ} 1,41-59$.

KAMBELE, Z., LI, G. y ZHOU, Z. (2015): «Travelers' Information-Seeking Behaviors». Journal of Travel \& Tourism Marketing, vol. 32, nº 1-2, 141-152.

KEATING, B. y KRIZ, A. (2008): «Outbound Tourism From China: Literature Review and Research Agenda». Journal of Hospitality and Tourism Management, vol. 15, $\mathrm{n}^{\circ}$ 01, $32-41$. 
KEATING, B.W., HUANG, S. (Sam), KRIZ, A. y HEUNG, V. (2015): «A Systematic Review of the Chinese Outbound Tourism Literature: 1983-2012». Journal of Travel \& Tourism Marketing, vol. 32, n 1-2, 2-17.

KIM, S.S., WAN, Y.K.P. y PAN, S. (2015): «Differences in Tourist Attitude and Behavior Between Mainland Chinese and Taiwanese Tourists». Journal of Travel \& Tourism Marketing, vol. 32, n 1-2, 100-119.

KING, B., DWYER, L. y PRIDEAUX, B. (2006): «An Evaluation of Unethical Business Practices in Australia's China Inbound Tourism Market». International Journal of Tourism Research, vol. 8, 127-142.

KING, B. y GARDINER, S. (2015): «Chinese International Students. An Avant-Garde of Independent Travellers?» International Journal of Tourism Research, vol. 17, 130-139.

KWEK, A. y LEE, Y.-S. (2008): «Intra-Cultural Variance of Chinese Tourists in Destination Image Project: Case of Queensland, Australia». Journal of Hospitality Marketing \& Management, vol. 16, $\mathrm{n}^{\circ} 1,105-135$.

KWEK, A. y LEE, Y.-S. (2010): «Chinese Tourists and Confucianism». Asia Pacific Journal of Tourism Research, vol. 15, n 2, 129-141.

KWEK, A. y LEE, Y.-S. (2015): «How «Face» Matters: Chinese Corporate Tourists in Australia». Journal of Travel \& Tourism Marketing, vol. 32, nº 1-2, 120-140.

LAI, C., LI, X. (Robert) y HARRILL, R. (2013): «Chinese outbound tourists' perceived constraints to visiting the United States». Tourism Management, vol. 37, 136-146.

LAW, R., TO, T. y GOH, C. (2008): «How do Mainland Chinese travelers choose restaurants in Hong Kong? An exploratory study of individual visit scheme travelers and packaged travelers». International Journal of Hospitality Management, vol. 27, n 3, 346-354.

LEE, S., JEON, S. y KIM, D. (2011): «The impact of tour quality and tourist satisfaction on tourist loyalty: The case of Chinese tourists in Korea». Tourism Management, vol. 32, $\mathrm{n}^{\circ}$ $5,1115-1124$.

LEIPER, N. (1979): «The framework of tourism». Annals of Tourism Research, vol. 6, n 4, 390-407.

LI, F. y RYAN, C. (2015): «Chinese Tourists' Motivations and Satisfaction of Visiting North Korea». Asia Pacific Journal of Tourism Research, vol. 20, n 12, 1313-1331.

LI, M. y CAI, L. (2012): «The Effects of Personal Values on Travel Motivation and Behavioral Intention». Journal of Travel Research, vol. 51, n 4, 473-487.

LI, M., QIU, S. (Charles) y LIU, Z. (2016): «The Chinese way of response to hospitality service failure: The effects of face and guanxi». International Journal of Hospitality Management, vol. 57, 18-29.

LI, M., WEN, T. y LEUNG, A. (2011a): «An Exploratory Study of the Travel Motivation of Chinese Female Outbound Tourists». Journal of China Tourism Research, vol. 7, no 4 , 411-424.

LI, M., ZHANG, H.Q. y CAI, L. (2013): «A Subcultural Analysis of Tourism Motivations». Journal of Hospitality \& Tourism Research, vol. XX, n X, 1-29.

LI, M., ZHANG, H.Q., MAO, I. y DENG, C. (2011b): «Segmenting Chinese Outbound Tourists by Perceived Constraints». Journal of Travel \& Tourism Marketing, vol. 28, ${ }^{\circ}$ 6, 629-643. 
LI, X. (Robert), CHENG, C.-K., KIM, H. y LI, X. (2012): «Positioning USA in the Chinese Outbound Travel Market». Journal of Hospitality \& Tourism Research, vol. 39, $\mathrm{n}^{\circ} 1$, 75-104.

LI, X. (Robert), LAI, C., HARRILL, R., KLINE, S. y WANG, L. (2011c): «When east meets west: An exploratory study on Chinese outbound tourists' travel expectations». Tourism Management, vol. 32, no 4, 741-749.

LI, X. (Robert) y STEPCHENKOVA, S. (2012): «Chinese Outbound Tourists' Destination Image of America: Part I». Journal of Travel Research, vol. 51, n 3, 250-266.

LIN, V.S., MAO, R. y SONG, H. (2015): «Tourism expenditure patterns in China». Annals of Tourism Research, vol. 55, 193.

LIN, Y.-C. y CHEN, C.-C. (2012): «Needs Assessment for Food and Food Services and Behavioral Intention of Chinese Group Tourists Who Visited Taiwan». Asia Pacific Journal of Tourism Research, vol. 19, $\mathrm{n}^{\circ}$ 1, 1-16.

LIN, Y.-H., CHEN, C.-C. y PARK, C.W. (2012): «The Salient and Organic Images of Taiwan as Perceived by Mainland Chinese Tourists». Asia Pacific Journal of Tourism Research, vol. $17, \mathrm{n}^{\circ} 4,381-393$.

LIU, G. y RYAN, C. (2011): «The Role of Chinese Students as Tourists and Hosts for Overseas Travel». Asia Pacific Journal of Tourism Research, vol. 16, n 4, 445-464.

LO, A., TSAI, H. y CHEUNG, C. (2013): «Service Quality of Casinos in Macau: From the Mainland Chinese Perspective». Journal of China Tourism Research, vol. 9, nº January 2015, 94-114.

LOI, K.I. y PEARCE, P.L. (2015): «Exploring Perceived Tensions Arising from Tourist Behaviors in a Chinese Context». Journal of Travel \& Tourism Marketing, vol. 32, 65-79.

LOJO, A. (2016): «Chinese tourism in Spain: An analysis of the tourism product, attractions and itineraries ofered by the Chinese travel agencies». Cuadernos de Turismo, $\mathrm{n}^{\circ} 37$, 243-268.

LÓPEZ-GUZMÁN, T., RODRÍGUEZ-GARCÍA, J. y VIEIRA-RODRÍGUEZ, Á. (2013): «Revisión de la literatura científica sobre enoturismo en España». Cuadernos de turismo, $n^{\circ} 32,171-188$.

LU, A.C.C. y CHEN, B.T. (2014): «Information Search Behavior of Independent Travelers: A Cross-Cultural Comparison Between Chinese, Japanese, and American Travelers»». Journal of Hospitality Marketing \& Management, vol. 23, $\mathrm{n}^{\circ}$ 8, 865-884.

LU, J., HUNG, K., WANG, L., SCHUETT, M.A. y HU, L. (2016): «Do perceptions of time affect outbound-travel motivations and intention? An investigation among Chinese seniors». Tourism Management, vol. 53, 1-12.

LU, Z. (2011): «The Study of Chinese Tourists' Motivations to Canada». Journal of China Tourism Research, vol. 7, no 4, 345-354.

MA, E., QU, C., HSIAO, A. y JIN, X. (2015): «Impacts of China Tourism Law on Chinese Outbound Travelers and Stakeholders: An Exploratory Discussion». Journal of China Tourism Research, vol. 11, n 3, 229-237.

MAK, B. (2013): «The Influence of Political Ideology on the Outbound Tourism in China». Journal of China Tourism Research, vol. 9, $\mathrm{n}^{\circ}$ 1, 1-26. 
MAO, I. y ZHANG, H.Q. (2014): «Structural Relationships among Destination Preference, Satisfaction and Loyalty in Chinese Tourists to Australia». International Journal of Tourism Research, vol. 16, 201-208.

MARCH, R. (2008): «Towards a Conceptualization of Unethical Marketing Practices in Tourism: a Case-Study of Australia's Inbound Chinese Travel Market». Journal of Travel \& Tourism Marketing, vol. 24, nº 4, 285-296.

MCKERCHER, B., LAW, R. y LAM, T. (2006): «Rating tourism and hospitality journals». Tourism Management, vol. 27, nº 6, 1235-1252.

MICHAEL HALL, C. (2011): «Publish and perish? Bibliometric analysis, journal ranking and the assessment of research quality in tourism». Tourism Management, vol. 32, $\mathrm{n}^{\circ} 1$, 16-27.

MICHAEL HALL, C. (2013): «Framing tourism geography: Notes from the underground». Annals of Tourism Research, vol. 43, 601-623.

MOHSIN, A. (2008): «Analysis of Chinese Travellers' Attitudes Toward Holidaying in New Zealand: The Impact of Socio-Demographic Variables». Journal of Hospitality \& Leisure Marketing, vol. 16, $\mathrm{n}^{\circ} 1-2,21-40$.

NGUYEN, T.H.H. y CHEUNG, C. (2016): «Chinese heritage tourists to heritage sites: what are the effects of heritage motivation and perceived authenticity on satisfaction?» Asia Pacific Journal of Tourism Research, 1-14.

O’ REGAN, M. y CHANG, H. (2015): «Smartphone Adoption amongst Chinese Youth during Leisure-based Tourism: Challenges and Opportunities». Journal of China Tourism Research, vol. 11, no 3, 238-254.

ONG, C.E. y DU CROS, H. (2012): «The Post-Mao gazes. Chinese Backpackers in Macau». Annals of Tourism Research, vol. 39, n 2, 735-754.

PARK, S.H., HSIEH, C.-M. y LEE, C.-K. (2016): «Examining Chinese College Students' Intention to Travel to Japan Using the Extended Theory of Planned Behavior: Testing Destination Image and the Mediating Role of Travel Constraints». Journal of Travel \& Tourism Marketing,

PARK, S.H., LEE, C.-K. y MILLER, J.C. (2015): «A comparative study of the motivations, activities, overall satisfaction, and post-trip behaviors of international tourists in Macau: Mainland Chinese, Hongkongese, Taiwanese, and Westerners». Asia Pacific Journal of Tourism Research, vol. 20, n 10, 1174-1193.

PEARCE, P.L. (2005): Tourist Behaviour. Themes and Conceptual Schemes. Clevedon, Channel View Publications.

PEARCE, P.L. y LU, H. (Ella) (2011): «A Framework for Studying the Learning Outcomes of Chinese Outbound Group Tourists». Journal of China Tourism Research, vol. 7, $\mathrm{n}^{\circ} 4$, 445-458.

PECHLANER, H., ZEHRER, A., MATZLER, K. y ABFALTER, D. (2004): «A Ranking of International Tourism and Hospitality Journals». Journal of Travel Research, vol. 42, 328-332.

PRAYAG, G., COHEN, S.A. y YAN, H. (2015a): «Potential Chinese travellers to Western Europe: segmenting motivations and service expectations». Current Issues in Tourism, vol. $18, \mathrm{n}^{\circ} 8,1-19$. 
PRAYAG, G., DISEGNA, M., COHEN, S.A. y YAN, H. (2015b): «Segmenting Markets by Bagged Clustering: Young Chinese Travelers to Western Europe». Journal of Travel Research, vol. 54, $\mathrm{n}^{\circ}$ 2, 234-250.

QIU, S., LI, M., HUANG, Z. (Joy) y DANG, N. (2015): «Impact of Tourism Openness Across the Taiwan Strait: Perspective of Mainland Chinese Tourists». Asia Pacific Journal of Tourism Research, vol. 20, $\mathrm{n}^{\circ}$ 1, 76-93.

ROWEN, I. (2014): «Tourism as a territorial strategy: The case of China and Taiwan». Annals of Tourism Research, vol. 46, 62-74.

RYAN, C. (2005): «The ranking and rating of academics and journals in tourism research». Tourism Management, vol. 26, nº 5, 657-662.

RYAN, C. y GU, H. (2007): «Spatial planning, mobilities and culture-Chinese and New Zealand student preferences for Californian travel». International Journal of Tourism Research, vol. 9, 189-203.

SAUNDERS, M., LEWIS, P. y THORNILL, A. (2012): Research methods for business students. Essex, Pearson Education.

SAUSMAREZ, N., TAO, H. y MCGRATH, P. (2012): «Chinese Outbound Tourism to the United Kingdom: Issues for Chinese and British Tour Operators». Journal of China Tourism Research, $\mathrm{n}^{\circ}$ 8, 268-283.

SHU, M. (Lavender) y SCOTT, N. (2014): «Influence of Social Media on Chinese Students' Choice of an Overseas Study Destination: An Information Adoption Model Perspective». Journal of Travel \& Tourism Marketing, vol. 31, 286-302.

SIU, G., LEE, L.Y.S. y LEUNG, D. (2013): «Residents' Perceptions Toward the «Chinese Tourists» Wave' in Hong Kong: An Exploratory Study». Asia Pacific Journal of Tourism Research, vol. 18, $\mathrm{n}^{\circ}$ 5, 446-463.

SONG, H. y HSU, C.H.C. (2013): «The Image of Taiwan as a Travel Destination: Perspectives from Mainland China». Journal of Travel \& Tourism Marketing, vol. 30, $\mathrm{n}^{\circ} 3$, 253-271.

SPARKS, B. y PAN, G.W. (2009): «Chinese Outbound tourists: Understanding their attitudes, constraints and use of information sources». Tourism Management, vol. 30, $\mathrm{n}^{\circ} 4$, 483-494.

STEPCHENKOVA, S. y LI, X. (Robert) (2012): «Chinese Outbound Tourists' Destination Image of America: Part II». Journal of Travel Research, vol. 51, $\mathrm{n}^{\circ}$ 6, 687-703.

SUN, M., RYAN, C. y PAN, S. (2015): «Using Chinese Travel Blogs to Examine Perceived Destination Image: The Case of New Zealand». Journal of Travel Research, vol. 54, $\mathrm{n}^{\circ}$ 4, 543-555.

SUN, M., ZHANG, X. y RYAN, C. (2014): «Perceiving tourist destination landscapes through Chinese eyes: The case of South Island, New Zealand». Tourism Management, vol. 46, 582-595.

THE WALL STREET JOURNAL (2015): «Chinese Tourists Will Spend \$229 Billion Abroad in 2015». The Wall Street Journal. Disponible en: http://blogs.wsj.com/chinarealtime/2015/09/29/chinese-tourists-will-spend-229-billion-abroad-in-2015/ [Consulta: 15 de mayo de 2016].

TRIBE, J. y LIBURD, J.J. (2016): «The tourism knowledge system». Annals of Tourism Research, vol. 57, 44-61. 
TRUONG, T.H. y KING, B. (2009): «An evaluation of satisfaction levels among Chinese tourists in Vietnam». International Journal of Tourism Research, vol. 11, $\mathrm{n}^{\circ}$ 6, 521-535.

TSANG, N.K.F., LEE, L.Y.S. y LIU, C.K.L. (2014): «Understanding the Shopping Motivation of Mainland Chinese Tourists in Hong Kong». Journal of China Tourism Research, vol. $10, \mathrm{n}^{\circ} 3,323-346$.

TSE, T.S.M. (2014): «Does Tourism Change Our Lives?» Asia Pacific Journal of Tourism Research, vol. 19, n 9, 989-1008.

TSE, T.S.M. (2015): «A Review of Chinese Outbound Tourism Research and the Way Forward». Journal of China Tourism Research, vol. 11, n 1, 1-18.

TSE, T.S.M. y HOBSON, J.S.P. (2008): «The Forces Shaping China's Outbound Tourism». Journal of China Tourism Research, vol. 4, n $2,136-155$.

TSE, T.S.M. y TSE, Q.K.T. (2015): «The Legal Aspects of «Zero-Fare» Tour in Shopping Tourism: A Case of Chinese Visitors in Hong Kong». Journal of China Tourism Research, vol. 11, no 3, 297-314.

UNWTO (2015): Growth of Chinese Tourist to Hong Kong, China, 2002 to 2014: implications and way forward. Madrid, World Tourism Organization.

URRY, J. y LARSEN, J. (2011): The tourist gaze 3.0. Thousand Oaks, CA, Sage Publications.

WAN, P.Y.K., KIM, S.S. y ELLIOT, S. (2013): «Behavioral Differences in Gaming Patterns among Chinese Subcultures as Perceived by Macao Casino Staff». Cornell Hospitality Quarterly, vol. 54, 358-369.

WANG, C., QU, H. y HSU, M.K. (2016a): «Toward an integrated model of tourist expectation formation and gender difference». Tourism Management, vol. 54, 58-71.

WANG, L., FONG, D. y LAW, R. (2015): «Travel Behaviors of Mainland Chinese Visitors to Macao». Journal of Travel \& Tourism Marketing, 1-13.

WANG, W., WU, W., LUO, J. y LU, J. (2016b): «Information technology usage, motivation, and intention: a case of Chinese urban senior outbound travelers in the Yangtze River Delta region». Asia Pacific Journal of Tourism Research, vol. 1665, $\mathrm{n}^{\circ}$ May, 1-17.

WANG, Y. y DAVIDSON, M.C.G. (2010): «Chinese Holiday Makers' Expenditure: Implications for Marketing and Management». Journal of Hospitality Marketing \& Management, vol. 19, n 4, 373-396.

WILLIAMS, S. y LEW, A.A. (2015): Tourism Geography: Critical Understandings of Place, Space and Experience. London, Routledge.

WONG, I.A. y LI, X. (2015): «Destination services and travel experience in the gaming mecca: The moderating role of gambling as a travel purpose among Chinese tourists». Journal of Travel \& Tourism Marketing, vol. 32, 80-99.

WONG, I.A. y ROSENBAUM, M.S. (2012): «Beyond Hardcore Gambling: Understanding Why Mainland Chinese Visit Casinos in Macau». Journal of Hospitality \& Tourism Research, vol. 36, $\mathrm{n}^{\mathrm{0}}$ 1, 32-51.

WU, M.-Y. (2015): «Driving an Unfamiliar Vehicle in an Unfamiliar Country: Exploring Chinese Recreational Vehicle Tourists' Safety Concerns and Coping Techniques in Australia». Journal of Travel Research, vol. 54, $\mathrm{n}^{\circ} 6,801-813$.

WU, M.-Y. y PEARCE, P.L. (2014a): «Chinese recreational vehicle users in Australia: A netnographic study of tourist motivation». Tourism Management, vol. 43, 22-35. 
WU, M.-Y. y PEARCE, P.L. (2014b): «Understanding chinese overseas recreational vehicle tourists: A Netnographic And Comparative Approach». Journal of Hospitality \& Tourism Research, 1-23.

XIE, Y. y LI, M. (2009): «Development of China's Outbound Tourism and the Characteristics of Its Tourist Flow». Journal of China Tourism Research, vol. 5, n 3, 226-242.

XU, F., MORGAN, M. y SONG, P. (2009): «Students' travel behaviour: A cross-cultural comparison of UK and China». International Journal of Tourism Research, vol. 11, $\mathrm{n}^{\circ} 3$, 255-268.

XU, Y. y MCGEHEE, N.G. (2012): «Shopping behavior of Chinese tourists visiting the United States: Letting the shoppers do the talking». Tourism Management, vol. 33, $\mathrm{n}^{\mathrm{o}} 2$, 427-430.

YANG, X., REEH, T. y KREISEL, W. (2011): «Cross-Cultural Perspectives on Promoting Festival Tourism-An Examination of Motives and Perceptions of Chinese Visitors Attending the Oktoberfest in Munich (Germany)». Journal of China Tourism Research, vol. 7, nº February 2015, 377-395.

YEUNG, S. y LEUNG, C. (2007): «Perception and Attitude of Hong Kong Hotel Guestcontact Employees Towards Tourists from Mainland China». International Journal of Tourism Research, vol. 9, 395-407.

YUN, D. y JOPPE, M. (2011): «Chinese perceptions of seven long-haul holiday destinations: Focusing on activities, knowledge, and interest». Journal of China Tourism Research, vol. $7, \mathrm{n}^{\circ} 4,459-489$.

ZENG, G. y GO, F. (2013): «Evolution of middle-class Chinese outbound travel preferences: An international perspective». Tourism Economics, vol. 19, n 2, 231-243.

ZENG, Z., PRENTICE, C. y KING, B. (2014): «To Gamble or Not? Perceptions of Macau Among Mainland Chinese and Hong Kong Visitors». International Journal of Tourism Research, vol. 16, 105-112.

ZHANG, C. y ZHANG, J. (2013): «Analysing Chinese citizens' intentions of outbound travel: a machine learning approach». Current Issues in Tourism, vol. 17, $\mathrm{n}^{\circ}$ 7, 592-609.

ZHANG, H.Q., HEUNG, V. y YAN, Y.Q. (2009a): «Play or not to play-An analysis of the mechanism of the zero-commission Chinese outbound tours through a game theory approach». Tourism Management, vol. 30, n 3, 366-371.

ZHANG, H.Q., YAN, Y.Q. y LI, Y. (2009b): «Understanding the mechanism behind the zerocommission Chinese outbound package tours: Evidence from case studies». International Journal of Contemporary Hospitality Management, vol. 21, $\mathrm{n}^{\circ}$ 6, 734-751.

ZHANG, J.J. y SHELTON, E.J. (2015): «Ordering the Disordered Subject: a Critique of Chinese Outbound Tourists as New Zealand seeks to Become China Ready». Tourism Analysis, vol. 20, 343-353.

ZHANG, Y. y MURPHY, P. (2009): «Supply-chain considerations in marketing underdeveloped regional destinations: A case study of Chinese tourism to the Goldfields region of Victoria». Tourism Management, vol. 30, nº 2, 278-287.

ZHU, D., XU, H. y JIANG, L. (2015): «Behind Buying: The Chinese Gaze on European Commodities». Asia Pacific Journal of Tourism Research, vol. 1665, nº February, 1-19. 